\title{
A incorporação de novos temas e saber es nos estudos em saúde coletiva: o caso do uso da categoria gênero
}

\author{
The incorporation of new themes and knowledge \\ at public health studies: the gender category case
}

Wilza Villela ${ }^{1}$

Simone M onteiro ${ }^{2}$ ElianeVargas ${ }^{2}$

\footnotetext{
${ }^{1}$ Programa de Pósgraduação em Saúde Coletiva, UNIFESP. Rua Borges Lagoa 1.341, Vila Clementino. 04038-034 São Paulo SP. wilza.vi@terra.com.br ${ }^{2}$ Laboratório deEducação em AmbienteeSaúde, Instituto O swaldo Cruz, Fiocruz.
}

Abstract Thisarticleaims to reflect how gender as a category has been incorporated into academic public health studies. The discussion is based on some characteristics of the public health area, such as: interdisciplinary approach, commitment to the demands of society; dialogue with health professionals and connection with health policiesimplemented in the country. With this in mind, a review of articles from the SciELO database was made referring to gender and health as descriptors. The articles were classified in terms of their focal theme, methods, groups studied and use of gender category. The results reveal some heterogeneity in the use of the category in the studies selected that eventually could be explained by the particularities of the area. Based on this discussion, this article intends to foster a reflection on the ways to improve a gender approach in public health studies so as to overcome the existing differences between knowledge accrued in various fields.

Key words Gender, Health, Interdisciplinary approach, Public health, Academic literature
Resumo Este artigo objetiva refletir sobrea incorporação da categoria gênero nos estudos acadêmicos em saúde col etiva, tendo por referência algumas das características da área, como a interdisciplinaridade, o compromisso com as demandas da sociedade, 0 diálogo com os trabalhadores de saúde e a sintonia com as políticas de saúde implementadas no país. Para tanto, foi realizado um levantamento dos artigos indexados na base SciELO que referem gênero e saúde como descritores, classificando-os quanto aos temas em foco, à abordagem metodológica, à população estudada e ao tipo de uso da categoria gênero. A análise dos resultados revela a heterogeneidadeno uso da categoria na produção acadêmica sel eciona$\mathrm{da}$, que, eventualmente, podeser explicada pelas especificidades da área. Pretende-se, com este trabaIho, fomentar a reflexão sobre maneiras de incrementar a abordagem de gênero nos estudos em saúde coletiva de modo a superar diferenças entre os campos de conhecimento.

Palavras-chave Gênero, Saúde, Interdisciplinaridade, Saúde coletiva, Produção acadêmica 


\section{Introdução}

A saúde coletiva no Brasil, enquanto área de conhe cimento e de práticas, é marcada pelo compromisso político com a redução das desigualdades em saúde e o caráter interdisciplinar da sua produção acadêmicaํ. Estruturada sobre o tripé epidemiologia, ciências humanas e sociais, política e planejamento, a saúde coletiva sebeneficia dos desenvolvimentos internos de cada uma das disciplinas que a constituem, bem como pelasinterações queas referidas disciplinas estabelecem entre si. No entanto, este não é um trajeto simples ou fácil, como indicam as reflexões sobreas possibilidades elimites da exploração das fronteiras disciplinares nos estudos em saúde coletiva. Luz ${ }^{2}$ ilustra essa perspectiva ao assinalar a menor validação do referencial híbrido dos modelos interpretativos acerca das políticas em saúde. $\mathrm{Na}$ sua visão, a ampliação da participação do movimento social no cenário político brasileiro tem contribuído para mudar essa tendência. Ao analisar a produção das idéias na área, Canesqui ${ }^{3}$ ressal ta a diversidade temática e de perspectivas teórico metodológicas das ciências sociais como um desafio para a concretização da interdisciplinaridade proposta na saúde coletiva. Olinto ${ }^{4}$, por sua vez, descreve as dificuldades de se operacionalizar, em epidemiologia, conceitos provenientes das ciências sociais, enquanto Sevalho e Castiel ${ }^{5}$ identificam aproximações e obstáculos para uma cooperação entre a epidemiologia ea antropologia. Em direção semelhante, Béhague et al. ${ }^{6}$ tratam das perspectivas de parceria entre pesquisadores dessas disciplinas com base nas lições epistemológicas adquiridas a partir deexperiências empíricas decooperação bemsucedidas. Para os autores, a convergência entre os saberes e as mudanças nos modos dominantes dos conhecimentos disciplinares pode favorecer a compreensão mais aprofundada e contextual izada dos problemas e soluções dos agravos à saúde.

Apesar destes desafios, a multidisciplinaridade fundante da saúde coletiva possibilita a multiplicação de objetos e estratégias metodológicas para a sua abordagem, reafirmando o propósito deuma reflexão crítica sobre os determinantes sociais do processo saúde doença e da sua tradução em ações que promovam a equidade em saúde.

0 engajamento político que marca a saúde coletiva brasileira éuma característica da também da produção do conhecimento na área ${ }^{7}$, dada a sua história construída nas discussões em torno da reforma sanitária brasileira e sua consolidação paralela à implementação e consolidação do Sistema Ú nico de Saúde brasileiro, SUS. A dupla inserção de vários atores na saúde col etiva en na reforma da saúde do país, e ainda o ideário comum, possibilitou o diálogo com os trabalhadores da saúde e a reflexão sobre a prática a partir das experiências concretas nos serviços de saúde. Tais características se mantêm atéhoje, bem como a escuta para as demandas dos movimentos sociais organizados e a sintonia com os temas trazidos pelos grupos mais afetados pelas iniquidades em saúde. Deste modo, a área se desenvolve ancorada em sujeitos concretos, múltiplos e instáveis, perpassados por conflitos de interesses sociais e políticos, os "sujeitoscoletivos-da-saúde" 8 .

Esteéo caso da problematização sobre a saúde das mulheres posta em pauta pelo movimento feminista brasileiro na década de setenta. N este período, a maioria dos países ocidentais passa por mudanças nos padrões de organização da vida social, encontrando-se as mulheres maciçamente presentes no mercado formal de trabalho e com capacidade de controlar a sua fecundidade. Das mudanças na inserção social das mulheres decorre a busca de maior liberdade individual e autonomia, para a qual um dos elementos nodais éa "re apropriação do corpo" ${ }^{\prime \prime}$, pela identificação do corpo como o lócus de origem e exercício da dominação sobre as mulheres, por meio do controle da sexualidade eda reprodução ${ }^{10}$. Dado serem as práticas de saúde as instâncias sociais autorizadas a intervirem sobre os corpos e produzirem verdades sobre os sujeitos a partir daí ${ }^{11}$, a construção de práticas de saúde que desafiassem o imaginário social sobre mulheres como prisioneiras da sua capacidade biológica de gestar e parir foi uma das principais estratégias políticas do feminismo.

As iniciativas de desvelar os modos como as práticas de saúde produziam uma concepção de mulher na qual toda a sua subjetividade estava subordinada à sua fisiologia reprodutiva é acompanhada de estudos que buscam mostrar a relação entre os problemas de saúde das mulheres e a sua condição de desigualdade frente aos homens. Do mesmo modo, começam a ganhar volume os estudos que abordam a saúde das mulheres não apenas na dimensão reprodutiva ou como uma parcela inespecífica da população, mas também como trabalhadoras e como sujeitos que têm necessidades de saúde além das reprodutivas. Em 2002, em artigo de revisão, Correa ${ }^{12}$ afirma que há mais de vinte anos têm sido pesquisados os efeitos da desigualdade de gênero sobre a saúde das muIheres. Esses estudos têm por pressuposto a saúde como um direito básico, portanto integrado à agenda mais ampla de luta por direitos, e a compreensão das desigualdades de gênero como um dos determinantes das desigualdades em saúde. 
A abordagem das mulheres como sujeitos sociais nas investigações em saúde é contemporânea da emergência da categoria gênero nos estudos acadê micos no âmbito das ciências sociais norte-americana e européia. Gênero, de acordo com estas contribuições, se refereao conjunto designificados sociais atribuídos à diferença sexual. As culturas atribuem valores e sentidos diversos à constituição anatômica e à participação de mulheres e homens na reprodução biológica, produzindo a criação de conceitos polares, dicotômicos e hierarquizados de feminino e masculino que determinam modos distintos de viver, adoecer e morrer. A utilização da categoria gênero na análise dos eventos de saúde encontra-se relacionada ao conceito de determinação social do processo saúde-doença.

A disseminação do uso da categoria gênero na análise dos fatos humanos tem mostrado que gênero não é uma categoria unívoca ou monolítica. A interpretação da origem e da natureza das relações desiguais entre homens e mulheres tem sido objeto de profícuos debates teóricos ${ }^{13}$. No entanto, existe um consenso de queesta categoria não se rebatesobreo objeto empírico mulher. Gênero trata de relações sociais em que mulheres e homens estão igual e mutuamente implicados. Essa disseminação também tem revelado a complexidade do uso da categoria, já que gênero interage com outras dimensões do sujeito, como classe social ecor/ raça/etnia, bem como com práticas cotidianas, como exercício da sexualidade e trabal ho, criando desigualdades também entre as mulheres ${ }^{14}$.

Tornar gênero um eixo transversal na investigação em saúde é uma aposta na possibilidade de que a produção de evidências sobre desigual dades em saúde entre mulheres e homens, decorrentes das desigualdades de gênero, seja capaz de impactar políticas públicas voltadas para a redução destas desigualdades.

Este artigo objetiva descrever aspectos da utilização da categoria gênero na produção acadêmica em saúde coletiva, visando identificar suas potencialidades em termos de resultados já alcançadose caminhos ainda a percorrer

\section{Procedimentos metodológicos}

O levantamento da produção acadêmica foi realizado na base de dados SciELO (Scientific Electronic Library Online), para o período de 1991 a 2008, deartigosque apresentavam o termo gênero esaúde em seus descritores. A opção pelo SciELO decorre do fato desta base eletrônica concentrar periódicos científicos, representativos dos diversos cam- pos do conhecimento, de grande parte da produção brasileira. A atual valorização por parte das instituições de ensino e pesquisa da publicação de artigos em periódicos de bases indexadas certamente contribui para a presença da produção nacional no SciELO.

A primeira etapa do levantamento consistiu na identificação dos artigos que continham o descritor gênero no campo "Todos os itens" (título, assunto e resumo) da base. Foram localizadas 540 referências. Desse total, foi feito uma seleção de 360 , a partir da eliminação dos artigos nos quais gênero dizia respeito a uma taxonomia do campo da biologia.

Do total de 360 artigos, foram selecionados aqueles que refletiam sobrea realidade brasileira, resultando num total de 307. Não foram feitas restrições quanto ao tipo de abordagem ou desenho de estudo, havendo a inclusão dos artigos de natureza empírica, teórico e/ou documental, nem quanto à área de origem da publicação, sendo incluídos artigos que usam as categorias gênero e saúde nos periódicos também das áreas de ciência humanas e sociais.

Foram selecionados apenas artigos originais, sendo excluídos às resenhas, entrevistas, editorial, opinião edebate. I gualmentea análisenão contempla seis artigos que trazem reflexões sobre gênero na literatura acadêmica em saúde, aos quais o presente artigo pretende se somar.

A segunda etapa do levantamento correspondeu à classificação dos 307 artigos segundo: ano de publicação, temática, abordagem metodológica, grupo social estudado euso da categoria gênero. Apósa verificação das freqüências simples de cada uma das categorias estudadas, foi feito um reagrupamento das temáticas e dos grupos sociais investigados, visando facilitar a realização de cruzamentos.

Os temas foram agregados em cinco categorias: 1) saúde sexual e reprodutiva e DST/aids; 2) agravos à saúde; 3) direito à saúde, 4) trabalho; 5) violência. A opção por esta categorização se baseia, respectivamente, no fato de que a saúde sexual e reprodutiva agrega os assuntos mais imediatamente identificados como propícios aos estudos de gênero, dada a origem desta categoria na discussão feminista sobre corpo, sexualidade e reprodução. A inclusão neste grupo dos estudos sobre DST/aids refere-se à sua inserção no campo da saúde sexual. A segunda categoria, relativa ao uso do termo gê nero para a compreensão de diversas situações de saúde e de doença, diz respeito à tradição da saúde coletiva na identificação dos determinantes sociais das con dições de saúde a partir da análise da distribuição dos agravos em grupos populacionais dis- 
tintos. Aí estão também contempladas doenças específicas, uso de drogas, inclusive medicamentos, e processos vitais, como envel hecimento. A categoria relativa ao direito à saúde corresponde a condições necessárias à produção da saúde, sendo incorporados os trabalhos sobre práticas de saúde (cuidados corporais, assistência e vigilância), educação e modelos assistenciais. As categorias trabalho e violência não foram agrupadas com as demais pelas especificidades dos seus objetos e da sua inserção na saúde coletiva, conforme indicam as reflexões sobre essas temáticas ${ }^{15,16}$.

As abordagens metodológicas foram classificadas deacordo com a descrição dos autores como qualitativas, quantitativas, quali-quanti ou teórico/documental, sendo incluídos nestaúltima categoria os estudos de demanda e cobertura das ações dos serviços públicos. Os grupos sociais foram reunidos em: profissionais (de saúde, educação e demais categorias), usuários (de serviço de saúde, escola, projeto social, dentre outros), populações específicas (militar, líder comunitário; índio, confinado, desportista) e população em geral (grupos indiferenciados), tendo em vista as frequências simples de cada uma destas categorias e o permanente diálogo da saúde coletiva com os sujeitos para quem se dirigem as práticas de saúde.

0 uso da categoria gênero foi classificado em três tipos: 1) relativo à descrição do sexo dos sujeitos estudados, 2) trata gênero como pressuposto; as análises referidas sobre as diferenças entre homens e mulheres não se apóiam em dados empíricos; 3) gênero é utilizado a partir do material empírico, como dispositivo interpretativo ou compreensivo das situações evidenciadas.

Os dados coletados foram armazenados e processados pelo Statistical Package for Social Science (SPSS) for Windows.

Existem limitações nestelevantamento enquanto revisão bibliográfica exaustiva. A perspectiva adotada cumpre o objetivo deindicar como a categoria gênero se apresenta nas publicações acadêmicas no âmbito da saúde coletiva. 0 desenvolvimento de outras proposições com recorte de gênero voltadas para a valorização das práticas em serviços e relatos de experiências, por exemplo, estão melhor documentadas nos anais dos congressos da área. Também não foram particularizados os suplementos temáticos específicos sobre estudos de gênero ou temas correlatos, referências importantes na consolidação desta linha de investigação, o que pode ter influenciado favoravelmente os resultados.
Algumas tendências da literatura sobre gênero e saúde

Existe um aumento progressivo no número de publicações que faz menção ao termo gênero e saúde durante o período analisado, que vai de 2 em 1991 a 74 em 2007, estando já em 38 para o ano de 2008.

0 termo gênero foi utilizado na abordagem de assuntos variados, tendo sido listados inicialmente 25 temas, dentre os quais "trabalho" aparece como o mais frequente, seguido de "saúde sexual e reprodutiva". A análise dos temas agregados segundo as categorias descritas acima indica a maior frequência nos estudos sobre "agravos a saúde" (31,9\%) esobre"saúde sexual ereprodutiva eDST / aids" (30,3\%), seguidos de direitos a saúde (16,6\%), trabalho $(12,4 \%)$ e violência $(8,8 \%)$. No grupo "agravos à saúde," prevalecem estudos sobre as doenças crônico degenerativas, e em "saúde sexual e reprodutiva", o maior número de artigos se refereao uso de contracepção ou de métodos de dupla proteção. No grupo de "direitos à saúde", destacase o tema "educação" com discussões sobre abordagens e conteúdos de ensino, principalmente do curso de enfermagem, e os temas direito à saúde, políticas de saúde e modelos assistenciais, em menor número. A tabela abaixo mostra a frequência relativa de cada categoria e o conjunto de temas incluído em cada uma.

0 aumento do número de artigos que referem o termo gênero durante o período estudado e a amplitude de temas abordados reflete o vigor da produção acadêmica da saúde coletiva brasileira e sua capacidade de absorção de novas idéias. Tal incremento e abrangência já haviam sido apontados por Aquino ${ }^{17}$, em trabalho semelhante realizado a partir de consultas às bases de grupos de pesquisa do CN Pq eartigos indexados em revistas da área de saúde coletiva.

Os estudos são predominantemente quantitativos, mulheres e homens são abordados com maior frequência do que apenas mulheres ou apenas homens. Dentre os dezoito grupos sociais estudados, a categoria "população em geral" é a mais frequente quando considerada de modo isolado; quando se consideram as categorias agregadas, "usuários" passa a ser o grupo mais estudado, seguido da população em geral e profissionais. A categoria "populações específicas" éa que apresenta o menor número de trabal hos e chama atenção a existência de um único artigo relativo à população indígena, e também apenas um referente a 
Tabela 1. Classificação dos temas dos 307 artigos selecionados.

\begin{tabular}{llcc}
\hline \multicolumn{1}{c}{ Temas } & \multicolumn{1}{c}{ Categoria } & N & $\%$ \\
\hline Agravos à saúde & $\begin{array}{l}\text { Crônicas degenerativas; outras doenças; saúde e doença; } \\
\text { drogas; medicamento; saúde mental; saúde infantil; } \\
\text { envelhecimento; }\end{array}$ & 98 & 31,9 \\
$\begin{array}{l}\text { Saúde sexual e } \\
\text { reprodutiva e DST/aids }\end{array}$ & $\begin{array}{l}\text { Saúde sexual e reprodutiva; sexualidade; maternidade; } \\
\text { homens; DST/aids; identidade }\end{array}$ & 93 & 30,3 \\
Direitos à saúde & $\begin{array}{l}\text { Cuidados; direito; vigilância; saúde; políticas; educação } \\
\text { física; educação; práticas de saúde }\end{array}$ & 51 & 16,6 \\
Trabalho & $\begin{array}{l}\text { Sexual; de gênero; homicídio; injúria; trauma } \\
\text { Violência }\end{array}$ & 27 & 12,4 \\
Total & & 307 & 100 \\
\hline
\end{tabular}

populações confinadas. Os temas são estudados de modo relativamente homogêneo entre as categorias população e usuários, mas quando se refere aos profissionais existe uma concentração de estudos nas categorias trabal ho e a saúde sexual e reprodutiva.

0 cruzamento entre tema e tipo de abordagem mostra um predomínio dos estudos qualitativos no grupo temático de saúde sexual e reprodutiva e de violência e dos estudos quantitativos no estudo das questões de saúde em geral. Os estudos sobre trabalho se utilizam das diferentes abordagens em proporções semel hantes e os estudos sobre direito à saúde são predominantemente documentais.

Os estudos que tomam mulheres ou homens como sujeitos de pesquisa estão concentrados nos grupos temáticos de saúde sexual e reprodutiva e de violência. Nos outros dois grupos, os estudos abordam predominantementemulheresehomens.

Existe um maior número de trabalhos que utiliza gênero como categoria interpretativa dos eventos de saúde de mulheres e homens, em que pese o número de estudos em que o termo gênero aponta apenas o sexo dos sujeitos investigados e o número menor de estudos que tomam gênero como pressuposto. 0 uso da categoria gênero como descritor de sexo está concentrado no grupo de estudos das doenças em geral, enquanto o uso como dispositivo interpretativo dos achados encontrase predominantemente nos estudos sobre saúde sexual e reprodutiva e violência. 0 uso de gênero como pressuposto teórico predomina nos estudos sobre trabal ho e também sobre saúde mental enquanto categoria isolada. Dentre os estudos sobre direito à saúde, não predomina um tipo de uso sobre 0 outro.

A Tabela 2 sumariza os achados relativos aos cruzamentos entretemas, tipo de abordagem egrupos sociais e tipos de uso da categoria gênero.

\section{U sos da categoria gênero na saúde coletiva}

O uso da categoria gênero no país segue ten dência internacional, estimulada pelo reconhecimento do sistema das Nações Unidas de que a desigualdade social entre homens e mulheres entrava 0 desenvolvimento das nações e pelo incentivo dado, por meio das suas agências, a realização de intervenções que busquem reduzir estas desigualdades ${ }^{18}$. A epidemia do HIV/aids e a necessidade de realização de estudos que subsidiem ações eficazes para o seu controle também constituem um importante impulsionador dos estudos orientados pela perspectiva degênero, em especial sobre saúde sexual e reprodutiva. A existência de mais dois periódicosa partir de 1998, a revista Ciência e Saúde Coletiva e a Revista Brasileira de Epidemiologia, contribuindo para o aumento do número de artigos indexadosno SciELO, devetambém ter beneficiando aque les que referem a categoria gênero a partir de 1999. I gualmente colaboraram para o incremento das investigações sobre gênero na área da saúde coletiva as iniciativas voltadas para a formação de re cursos humanos e treinamento em pesquisa ${ }^{19}$. 
Tabela 2. Tipos de uso da categoria gênero segundo temas, grupo social e abordagem metodológica.

\begin{tabular}{|c|c|c|c|c|}
\hline \multirow[b]{2}{*}{ Tema } & \multicolumn{4}{|c|}{ Uso de gênero (\%) } \\
\hline & Pressuposto & Analítico & Sexo & Total \\
\hline Saúde sexual reprodutiva e DST/aids & 15,3 & 43,9 & 7,2 & 30,2 \\
\hline Agravos à saúde & 47,5 & 11,7 & 71,0 & 31,8 \\
\hline Violência & 5,1 & 12,8 & 1,4 & 8,8 \\
\hline Trabalho & 16,9 & 13,9 & 4,3 & 12,3 \\
\hline Direitos à saúde & 15,3 & 17,8 & 15,9 & 16,9 \\
\hline Total & $100,0 \%$ & $100,0 \%$ & $100,0 \%$ & $100,0 \%$ \\
\hline \multicolumn{5}{|l|}{ Grupo social } \\
\hline População específica & 1,7 & 5,4 & 2,9 & 4,2 \\
\hline População geral & 20,3 & 38,9 & 37,7 & 35,1 \\
\hline Profissionais & 27,1 & 25,9 & 18,8 & 24,6 \\
\hline Usuários & 50,8 & 29,7 & 40,6 & 36,1 \\
\hline Total & $100,0 \%$ & $100,0 \%$ & $100,0 \%$ & $100,0 \%$ \\
\hline \multicolumn{5}{|l|}{ Abordagem } \\
\hline Documental & 23,7 & 26,7 & 1,4 & 20,5 \\
\hline Quali & 15,3 & 44,4 & & 28,9 \\
\hline Quanti & 59,3 & 23,9 & 97,1 & 47,1 \\
\hline Quanti-quali & 1,7 & 5,0 & 1,4 & 3,6 \\
\hline Total & $100,0 \%$ & $100,0 \%$ & $100,0 \%$ & $100,0 \%$ \\
\hline
\end{tabular}

O volume de trabalhos que tomam "usuários" como objeto indica o compromisso da saúde cole tiva com aqueles a quem se destinam as ações públicas; tendo em vista quecerca de um terço $(36,6 \%)$ dos estudos com usuários usa gênero como categoria interpretativa, pode-se inferir que este compromisso também considera que os seres humanos não são objetos naturais, mas sujeitos socialmentedeterminados, inclusive pelas determinações de gênero ${ }^{20}$.

Os estudos sobre "violência", com maior recorrência de estudos qualitativos e documentais, voltados para as mulheres e para adultos de ambos os sexos, a partir do uso majoritário do gênero como categoria interpretativa, reforçam a idéia de que gênero pode ser um importante dispositivo para a compreensão das desigualdades em saúde ${ }^{15}$.

0 uso do termo gênero em estudos que abordam mulheres e homens mostra que esta categoria não tem se rebatido sobre o sujeito mulher. No entanto, deve ser considerado que este resultado é, em parte, devido ao volume de artigos da categoria "agravos à saúde", que incluem os temas sobre as doenças em geral. Nos temas "saúde sexual e reprodutiva", "trabalho" e "violência", os estudos estão concentrados em mulherese, secundariamente, em homens, sugerindo que nestes grupos estão inseridos os pesquisadores mais comprometidos com a visibilidade dos agravos à saúde das mulheres derivados das desigualdades de gênero. Convergem com essa perspectiva os dados sobre as abordagens metodológicas que revelam um predomínio dos estudos qualitativos em relação às categorias "saúde sexual e reprodutiva eDST/aids", sendo que nesta categoria também prevalece o uso de gênero como dispositivo interpretativo dos achados (43,9\%). Por outro lado, entre os artigos definidos como quantitativos, concentram-se os "agravosà saúde" eo uso da categoria gênero como descritor de sexo (71\%).

0 uso do termo gênero como sinônimo desexo e sua concentração no grupo que investiga doenças em geral deve ser olhado com cuidado. Este grupo está composto de artigos que predominantemente se utilizam da abordagem quantitativa e pode-se supor uma simples mudança de nomenclatura que não corresponde à idéia de desnaturalização do feminino e do masculino que configura o núcleo de sentido da categoria gênero. Conformeadverte 0 linto ${ }^{4}$, gênero enfatiza um sistema de relações que pode ou não incluir sexo, enquanto sexo designa uma caracterização anátomo fisiológica. Portanto, são termos que expressam objetos distintos e assim devem ser incorporados nos estudos epidemiológicos. No entanto é necessário lembrar que existeuma correnteteórica defendida 
por al gumas autoras feministas ${ }^{21}$ que afirma que a categoria sexo não corresponde a nada no espaço social, dado que a diferença sexual no mundo humano é necessariamente marcada por significados culturais. Assim, sexo seria gênero desde sempre.

Para além das discussões teóricas entre sexo e gênero, não se pode negar a tensão entre as categorias gênero emulher que permeia al guns dos debates nos espaços de reflexão política feminista, a partir do argumento de que o uso acadêmico da categoria gênero despolitiza a discussão sobre a desigualdade das mulheres ${ }^{22}$. De fato, a redução das desigualdades de gênero implica ações dirigidas às mulheres. No entanto, um maior e melhor acesso à saúde, por exemplo, não necessariamente reduz as demais desigualdades derivadas das relações de gênero, em especial as que se inscrevem no terreno da subjetividade. Outro argumento que alimenta este debate se refere à demarcação, nem sempretão fácil, entreos espaços de produção acadêmica eda prática política. Segundo esta perspectiva, as desigualdades entre mulheres e homens derivam do modo como se organizam as relações degênero em contextos específicos, de modo queo seu estudo pode contribuir para o delineamento de ações voltadas para superá-las. Sem aprofundar esta discussão, vale ressaltar a importância de estudos empíricos que apontem diferenças nos perfis de saúde entre homens e mulheres visando identificar possíveis variações de percepções e práticas relativas ao gênero na compreensão dos fenômenos de saúde- doença entre os diferentes grupos da população.

A incorporação degênero como categoria analítica no campo da saúde coletiva está necessariamente marcada pela complexidade da própria categoria e pelas características da área. Existe a dificuldade real de operacionalização da categoria gê nero, em particular em estudos quantitativos, já que gênero não atua independente de outros determinantes sociais de desigualdades e, ao mesmo tempo, está implicado nas diversas dimensões, objetivas e subjetivas, do sujeito. A ancoragem da saúde coletiva nos saberes derivados da biomedicina, que têm como objetos corpos e não relações sociais, possibilita que estudos quantitativos ou epidemiológicos tragam seus resultados desagregados por sexo, embora nem sempre estes resultados permitam interpretações plausíveis sobre os modos como as desigualdades de gênero contribuíram de modo específico para um determinado resultado. Como correlato das limitações dos estudos quantitativos na abordagem de gênero, os estudos de saúde no campo das ciências humanas e sociais também nem sempre conseguem avançar na análise dos modos particulares como as relações de gênero se organizam em situações concretas eespecíficas, ede como esta organização reflete, interfere ou seinterconecta com as demais dinâmicas sociais de produção de desigualdades, por exemplo, pobreza e racismo ${ }^{23}$.

Atual mente, existeuma série de políticas voltadas para a saúde das mulheres e a agenda das diversas organizações sociais tem incluído o monitoramento e a análise da sua implementação com uma das atividades prioritárias. Entretanto, isto não tem repercutido nos trabal hos acadêmicos da área. Assim, cabe interrogar a respeito da escassez de trabalhos que incorporem a dimensão de gênero na análise de eventos em saúdemental, nos processos de envelhecimento ou mesmo para trabaIhos que tomam os jovens como objeto, situações de vida visivelmente atravessadas pelas desigualdades de gênero. Será quenós, defensores da transversalidade de gênero na análise dos eventos de saúde, não conseguimos ainda ser suficientemente convincentes?

\section{Comentáriosfinais}

O material aqui apresentado pode sugerir, num olhar panorâmico, a existência de uma dicotomia: de um lado, estudos qualitativos, que abordam temas relacionados à saúde sexual e reprodutiva, que tomam as mulheres como sujeitos da investigação e usam gênero como categoria interpretativa dos achados empíricos. Deoutro, estudos quantitativos, que abordam doenças abrangendo muIheres e homens, e usam gênero como sinônimo de sexo. No entanto, mais do que tomar esta suposta dicotomia como expressão de algum possível conflito de visões e perspectivas, pode-se perguntar sobre as dinâmicas internas àárea que operam, facilitando ou dificultando a transversalização do gênero esua utilização num conjunto maior de estudos.

Gênero se relaciona ao processo de construção de uma nova perspectiva sobremulheres ehomens que, na área da saúde, permite redimensionar as suas necessidades. Este processo resultou da atuação sinérgica de diferentes atores sociais em um momento específico, particularmenteno Brasil. 0 duplo tripé que caracteriza a saúde coletiva, um formado pela articulação de três corpos disciplinares, outro formado pela relação com serviços, com as institui ções acadêmicas e com política, re presenta a força da área, traduzida no desenvolvimento deintervenções, debate político e produção acadêmica. Todavia, em razão deste mesmo hibri- 
dismo, as realizações da área também são perme adas por tensões e desafios, que se expressam, por exemplo, na dificuldade de concretização da interdisciplinaridade, no que refere à integração de métodos e redefinição de objetos ${ }^{24}$. Considerando que o gênero éuma categoria oriunda das ciências sociais, recente, complexa e multifacetada, a sua incorporação e uso na saúde coletiva sem dúvida requer este esforço interdisciplinar.

Ao mesmo tempo, enquanto categoria elaborada pelo pensamento feminista, gênero carrega um compromisso político com as mulheres, e a força da sua utilização reside na possibilidade de oferecer novos ângulos de compreensão dos eventos da vida de mulheres e homens que ampliem a autonomia. Dito de outro modo, além de um convite ao esforço da interdisciplinaridade, gênero é um convite ao engajamento político.

0 contexto político que determina o cotidiano das mulheres brasileiras esuas necessidades de saúde, hoje, é bem diferente daquele que animou o debate feminista dos anos setenta e oitenta. Grande parte das reivindicações feministas foi absorvida pela sociedade. No que diz respeito à saúde, exceção do direito ao aborto, as demais demandas têm encontrado respostas nas formulações governamentai ${ }^{25}$. Ao mesmo tempo, propostas específicas de atenção à saúde das mulheres se encontram inseridas nas agendas de diversos movimentos sociais, como os movimentos por igualdade racial ou de luta contra o HIV/aids, por exemplo. $\mathrm{N}$ estes movimentos, as necessidades específicas de saúde das mulheres aí inseridas nem sempre são identificadas com o que seria a agenda atual do feminismo em relação à saúde. Nesta direção, é importante ressaltar que, se a proposta de transversalização de gênero nos estudos em saúde coletiva visa ampliar a compreensão da dinâmica doença, mas também produzir um conhecimento útil para a sociedade representada nos movimentos sociais, o diálogo entre feministas acadêmicas e mulheres dos diferentes movimentos que atuam na saúde deve ser atualizado.

Ao mesmo tempo, o panorama de oferta de atenção à saúde no país tem mudado, com uma ênfase crescente na expansão da atenção básica e das ações de promoção da saúde (promoção). Junto com a mudança deste panorama, surge um novo quadro conceitual no horizonte dos trabalhadores de saúde, em que os temas do cuidado, da humanização e da integralidade, numa acepção bem distinta da dos anos oitenta, substitui a idéia de atenção integral à mulher que orientou as primeiras realizações das feministas no campo da saú$\mathrm{de}^{26}$. Estas mudanças apontam para a necessidade da contínua atualização do debate em torno de uma produção acadêmica em saúde coletiva que se utilize da potencialidade de cada um dos ei xos que se articulam nos dois tripés que sustentam, visando à oferta de conhecimentos úteis para a promoção da equidade em saúde, para a qual a equidade de gênero é condição.

Um dos desafios postos por quem pretende refletir como a categoria gênero tem sido incorporada nos estudos da área de saúde coletiva brasileira é buscar acrescentar algo ao que já foi tão bem documentado por outros autores. Este artigo objetivou pensar a dinâmica dessa fecunda teia de saberes eações que constitui a saúde coletiva a partir de um ângulo específico, a incorporação do termo "gênero" na produção acadêmica. Com base nas considerações sobre o contexto de surgimento da categoria gênero e as características da área de saúde coletiva, é suposto existirem variações nas formas de incorporação desta categoria. Tais variações refletem a penetração dos discursos e práticas sobre gênero, enquanto categoria interpretativa, entre os atores dos diversos campos disci plinares que constituem a saúde coletiva. Esta visão é bem ilustrada pelos diferentes modos de utilização de gênero, as diversas abordagens metodológicas e as relações entre objetos e abordagens metodológicas apresentadas neste artigo.

Os resultados apresentados indicam a penetração do uso da categoria, ao mesmo tempo que sugerem a necessidade da intensificação do diálogo entre as disciplinas que compõem a área, visando um diálogo entre estas no sentido de ampliar as lentes pelas quais os sujeitos são investigados ${ }^{6} . \mathrm{Na}$ prática interdisciplinar, a integração entre as diferentes áreas do conhecimento é tão fundamental quanto 0 exercício teórico disciplinar ${ }^{27}$. A despeito dessa necessidade, é importante reconhecer que 0 uso de gênero em diferentes abordagens metodológicas e com grupos sociais distintos revela a flexibilidade da categoria e da própria saúde coletiva e suas disciplinas axiais.

Não houve, neste artigo, a pretensão de dimensionar o alcance ou o impacto da incorporação de gênero na produção em saúde coletiva. I gualmente, não houve intenção de fazer uma análise do conteúdo da produção científica sobre gênero no campo da saúde coletiva, pois isto também já foi feito anteriormente, e de modo brilhante. Este mapeamento da produção acadêmica nacional que utiliza a categoria gênero nas investigações sobre saúde buscou indicar possi bilidades de um diálogo que considere gênero como uma dimensão essencial ao entendimento do processo saúde-doença de homens e mulheres. Tal perspectiva está orien- 
tada pelo desafio de construir pontes entre saberes a partir das especificidades de cada área de conhecimento. Este trabal ho é um convite à reflexão coletiva sobre modos de fomentar uma abordagem de gênero nos estudos de saúde, capaz de superar as diferenças entre as áreas disciplinares. $\mathrm{N}$ esta direção, o olhar sobre a produção possibilita identificar áreas de permeabilidade nas fronteiras entre saberes diversos expressos na literatura analisada.

\section{Colaboradores}

W VillelaeSM onteiro conceberam o artigo. Asduas, junto com E Vargas, participaram do levantamento dos dados, análise e redação final do trabalho.

\section{Agradecimentos}

Gostaríamos de agradecer a colaboração de Zeneida Teixeira Pinto na sistematização dos dados.
Referências

1. Campos GWS. Saúde Pública e Saúde Coletiva: campo e núcleo de saberes e práticas. Cien Saude Colet 2000; 5(2):219-230.

2. Luz MT. Duas questões permanentes em um século de políticas de saúde no Brasil Republicano. Cien Saude Colet 2000; 5(2):293-312.

3. Canesqui AM. Ciências Sociais e Saúde no Brasil: Três décadas de ensino e Pesquisa. Cien Saude Colet 1998; 3(1):131-168.

4. Olinto MTA. Reflexões sobre o uso do conceito de gênero e/ou sexo na epidemiologia: um exemplo nos modelos hierarquizados de análise. Rev. Bras. Epidemio 1998; 1(2):161-169.

5. Sevalho G, Castiel LD. Epidemiologia e antropologia médica: a in(ter)disciplinaridade possível. In: César AP, Rabelo MC, organizadores. Antropologia da saúde: traçando identidade explorando fronteiras. Rio de Rio de Janeiro: Fiocruz/Relume Dumará; 1998. p. 47-69.

6. Béhague DP, Gonçalves H, Victora C. Anthropology and Epidemiology: learning epistemological lessons through a collaborative venture. Cien Saude Colet 2008, 13(6):1711-1717.

7. Paim J, Almeida-Filho N. A Crise da Saúde Pública e a utopia da Saúde Coletiva. Salvador: Casa da Saúde; 2000.

8. M inayo MCS. Estrutura e sujeito, determinismo e protagonismo histórico: uma reflexão sobre a práxis da saúde coletiva. Cien Saude Colet 2001; 6(1):7-19.

9. Ávila MB. Radicalização do Feminismo, Radicalização da Democracia. In: Reflexões Feministas para a Transformação Social. Cadernos de Crítica Feminista, 1(0). Recife: SOS-Corpo, Instituto Feminista para a Democracia; 2007. p. 248.

10. Gargallo F. Ideas Feministas Latinoamericanas. M éxico: Universidad Autonoma de la Ciudad de México; 2006.

11. Foucault M. História da Sexualidade 1. A Vontade de Saber. Rio de Janeiro: Graal; 1993.

12. Correa S. Gênero e Saúde: Campos em transição. In: Bruschini C, Unbehaum S, organizadores. Gênero, Democracia e Sociedade Brasileira. São Paulo: Fundação Carlos Chagas/Editora 34; 2002. p. 359-388. 
13. Fraser N. Unruly Practices: Power, Discourse, and Gender in Contemporary Social Theory. $2^{\text {nd }}$ edition. M innesota: U niversity of M innesota Press; 2008.

14. Femenías ML. Esbozo de um feminismo Latino-Americano. Rev. Estud Fem 2007; 15(1):11-25.

15. Schraiber LB, D'oliveira AFPL, Couto MT. Violência e saúde: estudos científicos recentes. Rev. Saude Publica 2006; (40):112-120.

16. M inayo-Gomez C, Thedim-Costa SM F. Incorporação das ciências sociais na produção de conhecimentos sobre trabalho e saúde. Cien Saude Colet 2003; 8(1):125-136.

17. Aquino EM. Gênero e saúde: perfil e tendências da produção científica no Brasil. Rev. Saude Publica 2006; 40:121-132.

18. UNFPA- ICPD. Programme of Action. Cairo: UNFPAICPD; 1994.

19. Heilborn ML, Barbosa RM. Sexuality Research Training in Brazil. In: Handbook of Sexuality Research Training Initiatives. New York: Social Science Research Council; 2003. p. 110-123.

20. Sen G, Ostlin P. Unequal, Unfair, Ineffective and Inefficient. Gender Inequity in $\mathrm{H}$ ealth: Why it exits and how we can change it. Report prepared for the WHO Commission on the Social Determinants of Health, September 2007. Available from: www.who.int/social determinants/resources/latest_publications

21. Butler J. Bodies that Matter. New York: Routledge; 1993.

22. Castilhos C. Oficina de trabalho sobre gênero, feminismo e movimentos sociais. [comunicação pessoal]. GT Gênero e Saúde da ABRASCO. Rio de Janeiro, UERJ, maio de 2008.

23. Giffin K. Pobreza, desigualdade e eqüidade em saúde: considerações a partir de uma perspectiva de gênero transversal. Cad. Saude Publica 2002; 18 (supl.):103-112.

24. Luz M. O Campo da Saúde Coletiva: Multidisciplinaridade, Interdisciplinaridade e Transdisciplinaridade de Saberes e Práticas. [acessado 2008 nov 17]. Disponível em: http://www2.ghc.com.br/GepNet/ nepetformacaoprofissionaltexto1.pdf

25. Villela W, Nilo A. Monitoramento da M etas da Ungass em Saúde Sexual e Reprodutiva: Avanços e Desafios para a Resposta Brasileira. GESTOS/UNFPA; 2008. [No prelo].

26. Villela W, Menicicci E. Gênero, saúde da Mulher e integralidade. Confluências e Desencontros. In: Pinheiro RE, Araujo R, organizadores. Razões Públicas para a integralidade em saúde: 0 cuidado como Valor. Rio de Janeiro: CEPESC/ABRASC0; 2007. p. 317-332.

27. M inayo M C, Assis, SG; Deslandes, SF, Souza ER. Possibilidades e dificuldades nas relações entre ciências sociais e epidemiologia. Cien Saude Colet 2003; 8(1):97-107. 